\title{
Kinetics of Solid Phase Reactions at High Pressure and Temperature
}

\author{
J. M. Zaug, D. L. Farber, C. K. Saw, B. L. Weeks
}

February 11, 2002

U.S. Department of Energy

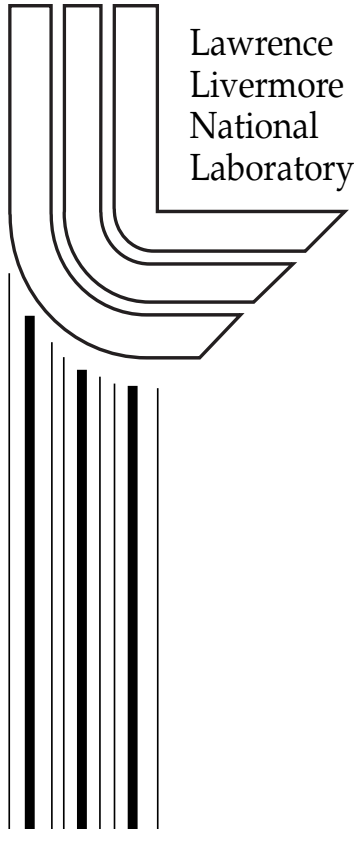




\section{DISCLAIMER}

This document was prepared as an account of work sponsored by an agency of the United States Government. Neither the United States Government nor the University of California nor any of their employees, makes any warranty, express or implied, or assumes any legal liability or responsibility for the accuracy, completeness, or usefulness of any information, apparatus, product, or process disclosed, or represents that its use would not infringe privately owned rights. Reference herein to any specific commercial product, process, or service by trade name, trademark, manufacturer, or otherwise, does not necessarily constitute or imply its endorsement, recommendation, or favoring by the United States Government or the University of California. The views and opinions of authors expressed herein do not necessarily state or reflect those of the United States Government or the University of California, and shall not be used for advertising or product endorsement purposes.

This work was performed under the auspices of the U. S. Department of Energy by the University of California, Lawrence Livermore National Laboratory under Contract No. W-7405-Eng-48.

This report has been reproduced directly from the best available copy.

Available electronically at http://www.doc.gov/bridge

Available for a processing fee to U.S. Department of Energy

And its contractors in paper from

U.S. Department of Energy

Office of Scientific and Technical Information

P.O. Box 62

Oak Ridge, TN 37831-0062

Telephone: (865) 576-8401

Facsimile: (865) 576-5728

E-mail: reports@adonis.osti.gov

Available for the sale to the public from

U.S. Department of Commerce

National Technical Information Service

5285 Port Royal Road

Springfield, VA 22161

Telephone: (800) 553-6847

Facsimile: (703) 605-6900

E-mail: orders@ntis.fedworld.gov

Online ordering: http://www.ntis.gov/ordering.htm

\section{OR}

Lawrence Livermore National Laboratory

Technical Information Department's Digital Library

http://www.llnl.gov/tid/Library.html 


\title{
KINETICS OF SOLID PHASE REACTIONS AT HIGH PRESSURE AND TEMPERATURE
}

\author{
J. M. Zaug, D. L. Farber, C. K. Saw, and B. L Weeks \\ University of California, Lawrence Livermore National Laboratory, \\ 7000 East Ave., Livermore, CA 94550
}

\begin{abstract}
We report on the subject of temperature and/or pressure induced solid-solid phase transitions of energetic molecular crystals. Over the last three years we have applied experimental techniques that when used simultaneously provide insight into some of the complexities that govern reaction rate processes. After more than 55 years of study a global kinetics model describing the P-T phase space transition kinetics of such materials as HMX (octahydro-1,3,5,7tetranitro-1,3,5,7-tetrazocine) is not only missing, but from a formal perspective is perhaps as many years away from completion. The essence of this report describes what material parameters affect first-order reaction rates of the CHNO moiety of molecular crystals and introduces the application of new experimental tools thus permitting quantifiable studies of important rate limiting mechanisms.
\end{abstract}

\section{INTRODUCTION}

From a basic science standpoint, understanding how chemical and mechanical processes compete and contribute to the emergent or measured rate of solidsolid first order phase transitions in large molecular organic crystal systems is as complex as it is interesting. After several decades of study on such processes, there is no established universal set of rate laws governing solid-solid structural phase transitions of polymer blended explosive (PBX) materials. The following parameters all affect the solid phase transformation kinetics of energetic molecular crystals (EMCs) at fixed pressure and temperature: grain size or surface energy, defect density, polymer binder content, impurity content, gas or liquid phase environment at 1-bar, and compaction density of a pressed crystalline powder. There is not a kinetics-based model that incorporates all of these critical rate-limiting parameters for common stockpile materials such as octahydro1,3,5,7-tetranitro-1,3,5,7-tetrazocine, (HMX). Given the core mission of the stockpile safety initiative we have been motivated to develop and refine a series of experimental diagnostic tools that will allow us to derive a universal rate law describing the decomposition of EMCs. It is possible to systematically develop a scientifically based global kinetics models for a complex organic molecular system, provided that one can be allowed to focus entirely on the processes steadily over the course of several years using multiple experimental tools.

Research into the dynamic behavior of energetic materials is an important area in propulsion, chemistry, and physics. However, this effort is made complicated by the large range of structural phases observed in many crystalline solids. For example, HMX is one of the most common energetic materials and exists in $\alpha, \beta, \gamma$, and $\delta$ polymorphic forms. The most stable room temperature form is the $\beta$ phase where the eight-membered ring HMX molecules exist in a quasi-chair form giving the molecule a center of symmetry. ${ }^{1}$ Under certain conditions the pure monoclinic $\beta$ phase undergoes a solid-solid transition into hexagonal $\delta$-HMX at $157^{\circ} \mathrm{C}$ and ambient pressure. In the $\delta$ phase, HMX displays a quasi-boat conformation where all of the $\mathrm{NO}_{2}$ groups reside on one side of the ring. ${ }^{2}$ The structure of the $\alpha$ and $\gamma$ phases $^{3}$ may also play a role in thermal decomposition at high pressure and temperature.

The $\beta$ to $\delta$ phase transition is thought to couple with the thermal decomposition of HMX and the transition temperature and rate can strongly depend on the grain size distribution of the $\beta$ phase. ${ }^{4}$ It is well known that $\delta$ HMX is more sensitive to initiation. $^{5}$ A $6.7 \%$ volume expansion ${ }^{6}$ associated with the phase transition leads to strain development and microfracturing of the crystalline surface. This mechanical damage is not necessarily associated with slow thermal decomposition, but can lead to a material with very different physical properties compared to the original starting material. Therefore, the mechanical properties and combustion/detonation characteristics of HMX can be affected by this transition. Moreover, the dramatic increase in void space of the $\delta$ phase also decreases the initiation threshold level and therefore safety becomes an outstanding issue to address. Studies performed by Palmer and Field describe the mechanical properties of single crystal $\beta$-HMX in detail. ${ }^{7}$ We have observed that when the defect density of HMX single crystals exceeds a certain threshold, grain size issues then become of secondary importance to the overall transition kinetics. Under these conditions nucleation and growth processes within the bulk of a sample dominate the free energy associated with larger grain crystals. There remains the possibility of determining the conditions where defect density and surface energy equally contribute to observed transition rates.

There have been other independent studies conducted on pure HMX single crystals that indicate chemical decomposition precedes structural reorientation. Two such examples are thermal reaction studies under a reducing gas environment ${ }^{8}$ and another conducted in vacuum?. In the first study HMX was brought up to 
temperature in a $95 \% \mathrm{~N}_{2}$, and $5 \% \mathrm{H}_{2}$ gas environment on a thermographic analyzer. Results seem to indicate that there exists a reversible $\mathrm{NO}_{2}$ caged reaction and hydrogen diffusion into the HMX matrix scavenges $\mathrm{NO}_{2}$ radicals. In the second study $\mathrm{HMX}$ was taken up to $200^{\circ} \mathrm{C}$ in a few milli-torr of vacuum. Under this condition the beta phase appears, under optical observation, to remain intact. Once a small amount of atmospheric gas is allowed to leak into the chamber the beta to delta phase transition occurs instantly. It appears from these two studies that chemistry or irreversible bond breaking precedes the structural transition in organic molecular crystals. The application of pressure (e.g., 2-3 kbars at ambient temperature) can reverse the polymorphic transition from $\delta$-HMX back to $\beta$-HMX.

\section{EXPERIMENTAL}

Three different experiments were employed over the course of this work to study the kinetics of solidsolid phase transitions in HMX, X-ray powder diffraction (XRPD), second harmonic generation (SHG), and atomic force microscopy (AFM). We also studied a second organic molecular crystal 1,3,5triamino-2,4,6-trinitrobenzene,(TATB), using XRPD, and a PBX material LX-04 composed of 84\% HMX and $16 \%$ Viton-A polymer binder was studied using SHG. SHG and XRPD experiments were conducted in hydrothermal diamond anvil cells (HDACs) (Figure 1). Pressure was applied using a hydraulic piston, which has the advantage of maintaining cell alignment during the entirety of an experiment.

SHG has been used to monitor what was perceived to be phase transitions of HMX and TATB. ${ }^{10,11}$ We implemented a system to collect SHG and XRPD data simultaneously (Figure 2.). SHG is inherently a surface sensitive time-resolved probe while XRPD monitors structure and volume with less temporal resolution. Pressure determinations are made by monitoring wavelength shifts in ruby fluorescence spectra of $<2 \mu \mathrm{m}$, ruby chips (excited by the $488 \mathrm{~nm}$ $\mathrm{Ar}^{+}$laser line) imbedded in powdered samples. Both SHG and XRPD systems are aligned with their respective source beams (500-micron diameter) collinear and incident onto the sample located in a HDAC. The output train of a Nd:YAG laser, (1064 $\mathrm{nm}, 2-4 \mathrm{~mJ}, 20 \mathrm{~Hz}$ pulse repetition frequency), illuminates HDAC enclosed samples and frequency doubled or SHG light is collected using a specially notched Be mirror that passes the primary x-ray beam. Output signals from a PMT and photodiode are collected using a Tektronix TDS684C oscilloscope and recorded to an Apple G4 computer using GPIB port interface and LabView $^{\mathrm{TM}}$ v5.1 software. Temperature is monitored using two thermocouples (TCs) one each mounted on opposing diamonds at a distance of approximately $2 \mathrm{~mm}$ away from samples. The temperature difference between

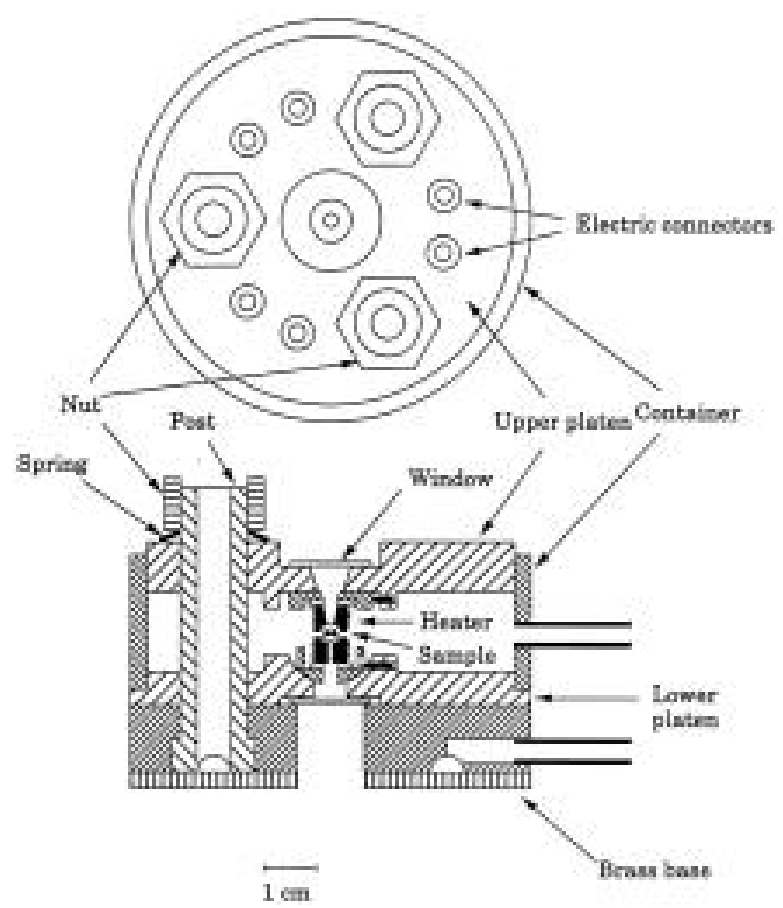

Fig. 1. Plan and elevation of hydrothermal diamond anvil cell. The cell was designed at Cornell University (W. A. Bassett et al., R.S.I., 64(8) 2340-2345, 1993.) to have high dimensional stability within the sample chamber throughout the temperature range, ease of alignment, efficient delivery of heat to the sample chamber with excellent temperature balance between anvils including high precision and accuracy temperature measurements.

TCs is $<0.2^{\circ} \mathrm{C}$. Two Eurotherm phase angle shifted temperature controllers are coupled via RS485 serial communication and employed to maintain a selected temperature. A $17 \mathrm{kev}$ monochromatic x-ray beam is collimated to 500 microns and directed into samples. X-ray patterns are angle diffracted onto Fuji image plates (IPs) and are developed on an IP reader with 50 $\mu \mathrm{m}$ pixel resolution. The $\mathrm{x}$-ray flux is not high enough to radiation damage our samples. Both experiments are performed simultaneously and interrupted only to replace IPs after completion of an 8-minute exposure sequence. Experiments begin at room temperature followed by a very rapid temperature jump to a target temperature. Temperature is steadily maintained $\left( \pm 0.2^{\circ} \mathrm{C}\right)$ throughout the duration of our experiments. Results reported here on TATB involved incremental increases of the temperature over time. We also independently ran SHG experiments on HMX and LX-04 at elevated temperatures using pressure to back transition the larger volume delta phase to the beta phase.

AFM was employed to study the surface morphology of EMCs undergoing solid-solid phase transformations. The advent of AFM provides a rather 


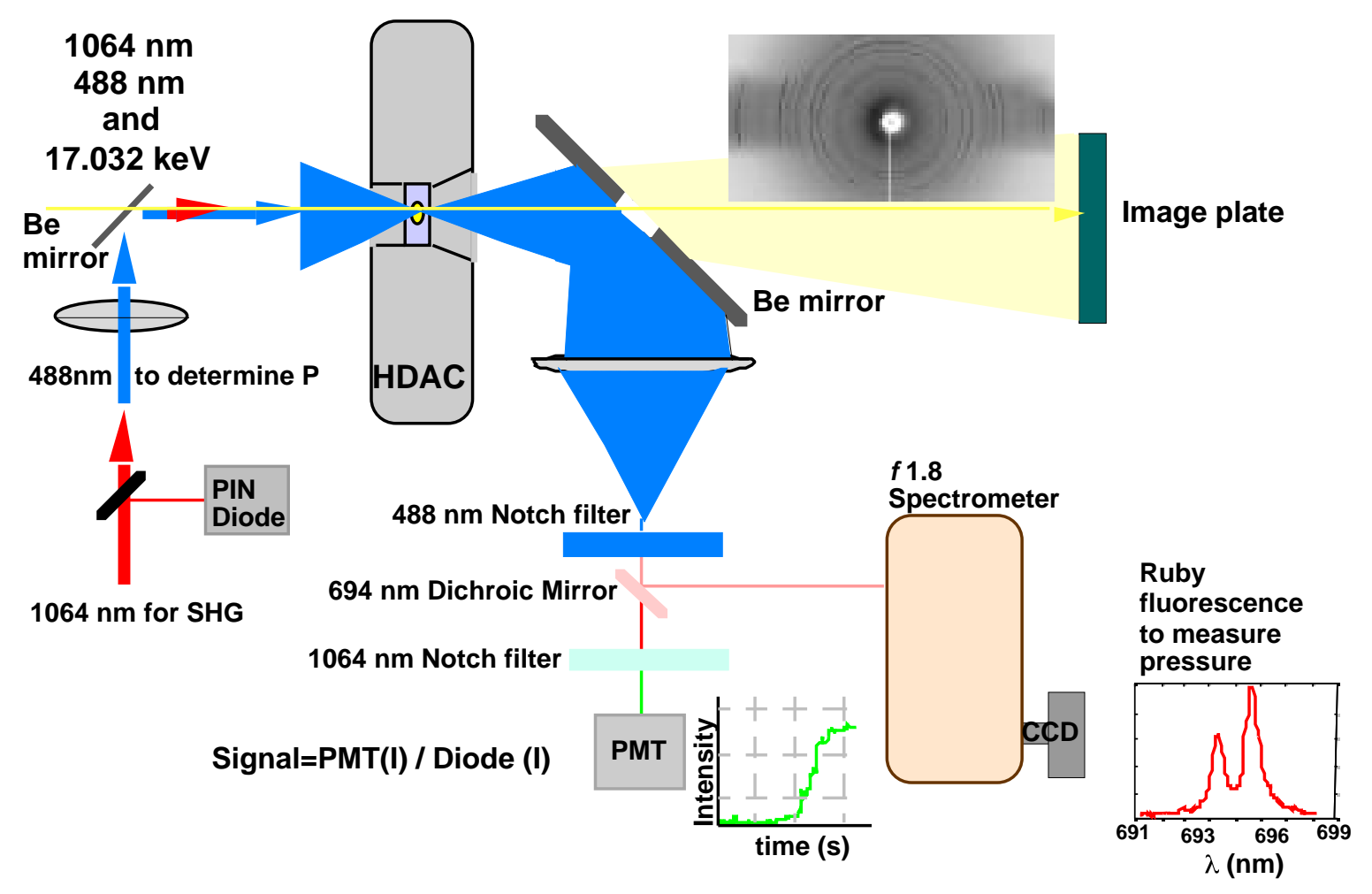

Fig. 2.SHG/XRPD schematic diagram. A Nd:YAG laser is used to probe the SHG efficiency of the HDAC encapsulated sample while a highflux X-ray beam is used to expose XRPD patterns on an image plate. The SHG data are normalized by laser fluctuations and XRPD exposures were 8 minutes in duration. A second argon ion laser is used to measure pressure shifted ruby fluorescence spectra. This experiment was conducted at the Stanford Sychrotron Radiation Laboratory on beamline 10-2.

precise tool to obtain images of the microstructure of surfaces $^{12}$ on energetic materials. AFM has been utilized to determine defects, plastic flow and failures on RDX crystalline explosives. ${ }^{13,14,15}$ AFM has also been used to observe crystal growth in real-time elucidating mechanisms and imperfections on crystal surfaces. ${ }^{16,17}$ On biological samples, AFM has been employed to observe solid-solid phase transitions insitu at room temperature. ${ }^{18}$ One drawback of AFM is that the instrument is not only susceptible to thermal drift, but the fine positioning piezo transducers depolarize at temperatures in excess of $150^{\circ} \mathrm{C}$. Conceivably the surface of HMX could be monitored during the $\beta / \delta$ phase transition if a suitable high temperature system could be found. Our AFM measurements were performed with a Digital Instruments MultiMode ${ }^{\mathrm{TM}}$ AFM equipped with a new high temperature heating assembly. ${ }^{9}$ The system incorporates forced water piezo cooling and is capable of sample temperatures up to $250^{\circ} \mathrm{C}$. Images were collected in TappingMode ${ }^{\mathrm{TM}}$ and the cantilever was heated to the same temperature as the sample to minimize thermal gradients and drifts, and also to prevent condensation.

HMX was prepared by the method of Siele et al., Propell. and Explosiv., (1981), 6, 67-73. This involved the treatment of Octahydro-1,5-diacetyl-3,7dinitro-1,3,5,7-tetrazocine (DADN) with $100 \% \mathrm{HNO}_{3}$ and $\mathrm{P}_{2} \mathrm{O}_{5}$ at $50^{\circ} \mathrm{C}$ for $50 \mathrm{~min}$. followed by quenching in ice water. Slow recrystallization from acetone yielded HMX as colorless microcrystals. The grain size distribution is trimodal Fig.3. TATB was prepared by aqueous amination of TCTNB in a water/nitrobenzene medium. The grain size distribution has a quasi-Gaussian profile centered at approximately 75 microns.

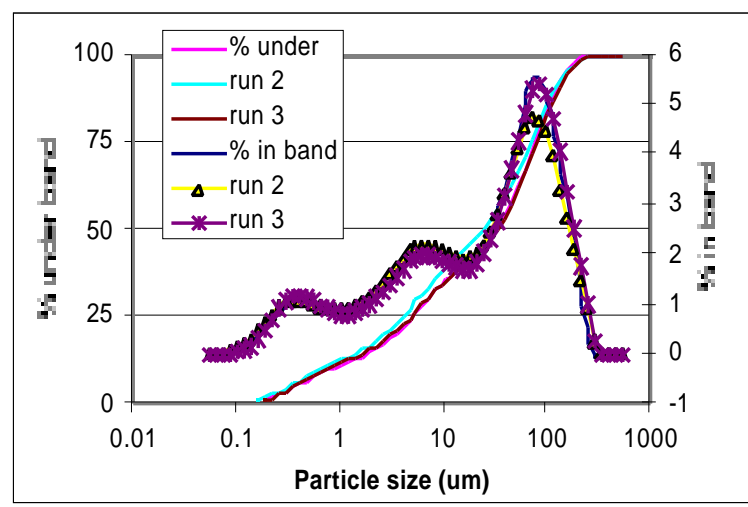

Figure 3: Grain size distribution of HMX lot \# B-725.

TATB, LX-04, and HMX powders were introduced into a 500-micron diameter rhenium gasket, 100 microns thick that laterally confines samples within the HDAC.

For our AFM studies pure $\beta$-HMX crystals were aligned such that the long axis was parallel to the fast 
scan direction of the AFM. Images were first obtained at room temperature to determine both crystal and tip quality. Figure 4 shows a room

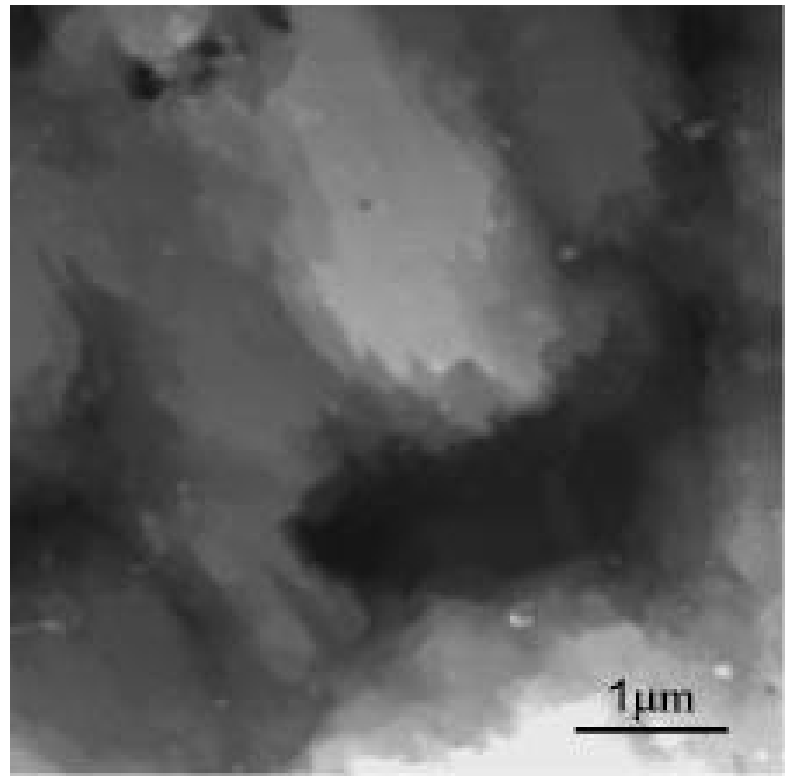

Figure 4: Room temperature AFM image of $\beta$-HMX. The $\mathrm{z}$ scale is $150 \mathrm{~nm}$ from light to dark.

temperature $5 \times 5 \mu \mathrm{m}$ image of a $\beta$-HMX crystal. The crystal was approximately $250 \mu \mathrm{m}$ in length and 45 $\mu \mathrm{m}$ in width. The sample was then heated to $145^{\circ} \mathrm{C}$ and equilibrated for 30 minutes. This temperature was chosen because it is well below the 1-bar solidsolid transition temperature. The thermal equilibration period is necessary to reduce thermal drift, which causes distortions or inhibits image quality. The sample was then heated above the transition temperature and a series of images were sequentially collected every 3 minutes.

\section{RESULTS AND DISCUSSION}

Figure 5 shows $x$-ray spectra for TATB with increasing temperatures at $20^{\circ} \mathrm{C}$ increments. The $2 \theta$ data extends to $25^{\circ}$. Each spectrum is acquired for 8 minutes. Listed in the plot is the JCPDS listing for TATB (43-1708). The major diffraction lines can be accounted for by the JCPDS listing for TATB. (TATB is triclinic with $\mathrm{a}=9.01 \mathrm{~b}=9.028$ and $\mathrm{c}=6.812(\AA), \alpha=108.59, \beta=91.82$ and $\gamma=119.97$.). A few less intense unidentified lines are perhaps from the background. The data does not substantiate the existence of a solid-solid phase transformation at these temperatures and grain size distribution. However, a shift of the (002) peak position to higher $\mathrm{d}$-spacings is observed with increasing temperature as shown in Figure 6. This result suggests the opening of the intermolecular distances with temperature. There appears to be only small changes in the (-211) and (2-11) peaks, which is consistent to

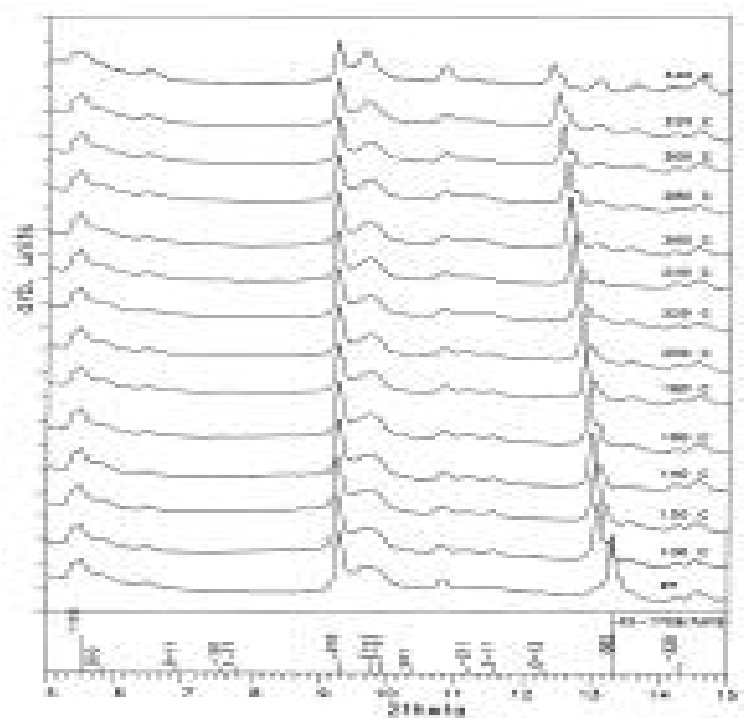

Figure 5: Truncated XRPD patterns of TATB to $340^{\circ} \mathrm{C}$. The JCPDS listed intensities are multiplied by ten.

the changes in the stacking in the c-direction. The lack of significant change in (hk0) peaks, which are related to inter-molecular arrangement, indicate no difference in molecular conformation up to $340^{\circ} \mathrm{C}$. The (002) line shifts, and increase in (004) peak intensity observed by S. Son et al. ${ }^{11}$ cannot be interpreted as a phase transformation but merely a reorganization of the triclinic phase. The molecular stacking distance associated with the c-lattice parameter increases with temperature. The linear coefficient of thermal expansion $\alpha_{\mathrm{c}}$ from a linear fit of the data in figure 6 is $225 \times 10^{-6} /{ }^{\circ} \mathrm{C}$. Most of the volume expansion in TATB occurs along the c-axis due to weak interplanar Van der Waals interactions and the absence of stronger intermolecular hydrogen bonds between planes.

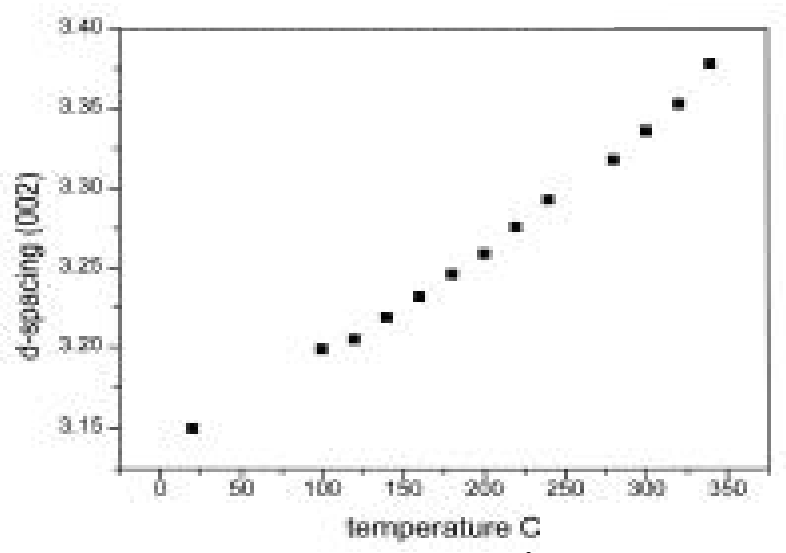

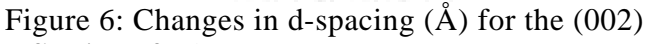
reflection of TATB.

Figure 7 shows the diffraction patterns for HMX held at $165^{\circ} \mathrm{C}$ as a function of time in seconds as indicated on the right side of the plot. These patterns 


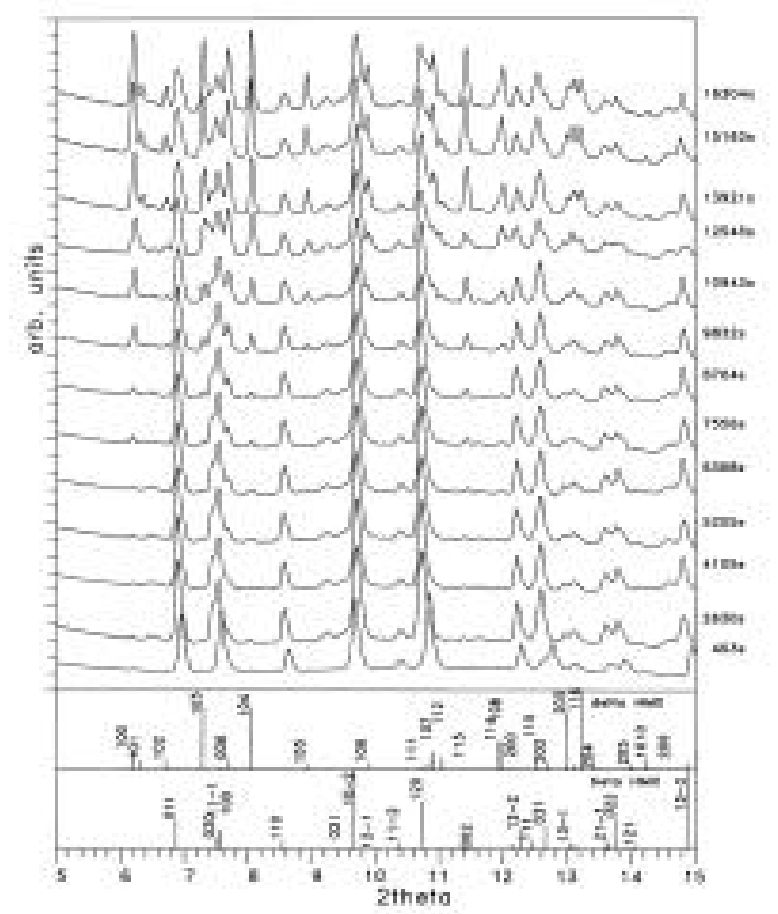

Figure 7: Truncated XRD patterns for $\mathrm{HMX}$ at $165^{\circ} \mathrm{C}$ versus time with the peak listing for the calculated powder patterns from published single crystal data.

are compared to the calculated powder pattern from single crystal results $[5,6]$ for both $\beta$ and $\delta$ phases using LAZY-PULVERIC programs as well as the JCPDS listing for HMX (PDF42-1768). Clearly, at the start of the experiment, all the lines can be accounted for by $\beta$ HMX as indicated. For simplicity, the number of spectra is reduced. The experiment ran for 4.7 hours at which point the synchrotron beam was shut down by SSRL for beam maintenance.

Figure 8 shows the normalized SHG signal and four HMX diffraction line intensities ( 001 and $-122 \beta$ lines, 100 and $113 \delta$-lines). The structure in the SHG growth curve is real and is either caused by grain scale effects and/or chemical decomposition product formation that affects electric field fidelity and hence

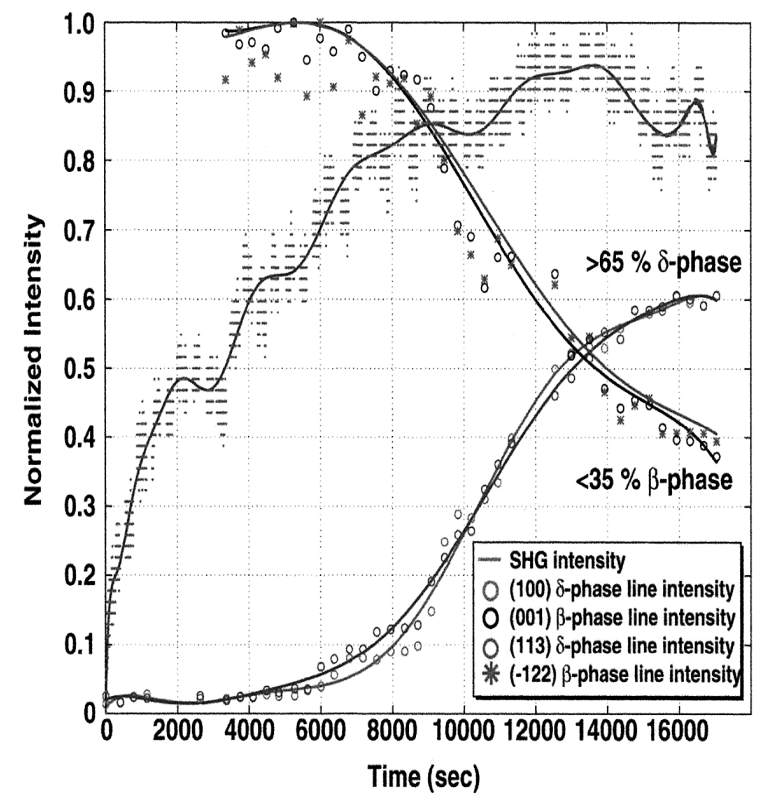

Figure 8: Normalized SHG intensity and XRD peak intensity ratios versus time at $165^{\circ} \mathrm{C}$.

SHG output intensity. The SHG data suggests that $80 \%$ of the HMX has converted to the delta phase after $\sim 8000$ seconds while the XRPD data (peak intensity ratios for $\beta$ and $\delta$ phase lines indicate phase concentration) indicates less than $15 \%$ of the sample volume converted. Also note that SHG intensity increases at the onset of the experiment.

One author (B.L.W.) conducted in situ hightemperature AFM experiments on HMX single crystals. The data implies that the total surface area of $\delta$-HMX can be on the order of $10^{3}$ to $10^{5}$ times higher than the starting $\beta$-HMX material. Figure 9 shows a series of images collected at $184^{\circ} \mathrm{C}$. Images are obtained on the (010) face of the monoclinic HMX crystal. The time between each image is indicated along with the rms roughness value. The $\mathrm{z}-$ scale is the same in each image $(500 \mathrm{~nm}$ from black to white). The voids in the surface open, and are orthogonal to the a-axis of the crystal. Also, an increase in the step height (from the bottom of the

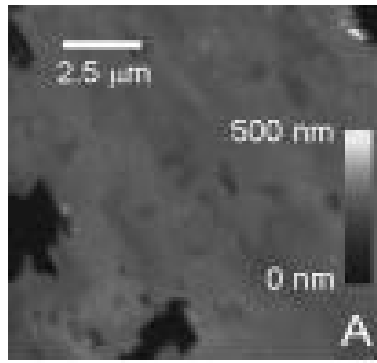

$\mathrm{t}=0, \mathrm{rms}=85 \mathrm{~nm}$

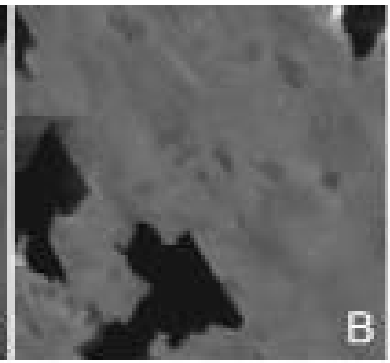

$\mathrm{t}=15 \mathrm{~min}, \mathrm{rms}=119 \mathrm{~nm}$

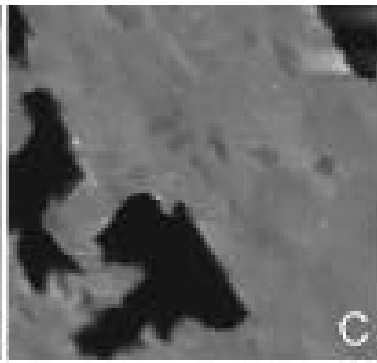

$\mathrm{t}=23 \mathrm{~min}, \mathrm{rms}=148 \mathrm{~nm}$

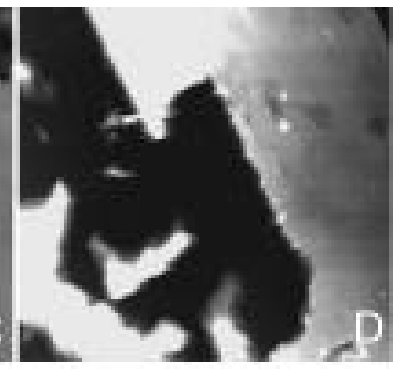

$\mathrm{t}=60 \mathrm{~min}, \mathrm{rms}=228 \mathrm{~nm}$

Figure 9: Series of images collected at $184^{\circ} \mathrm{C}$ showing the morphological surface effects of a solid-solid phase transition of HMX. The crystal is imaged on the (010) axis of $\beta$-HMX and is aligned such that the long axis runs from the top to bottom of the image. The scale is the same in each image for comparison. 


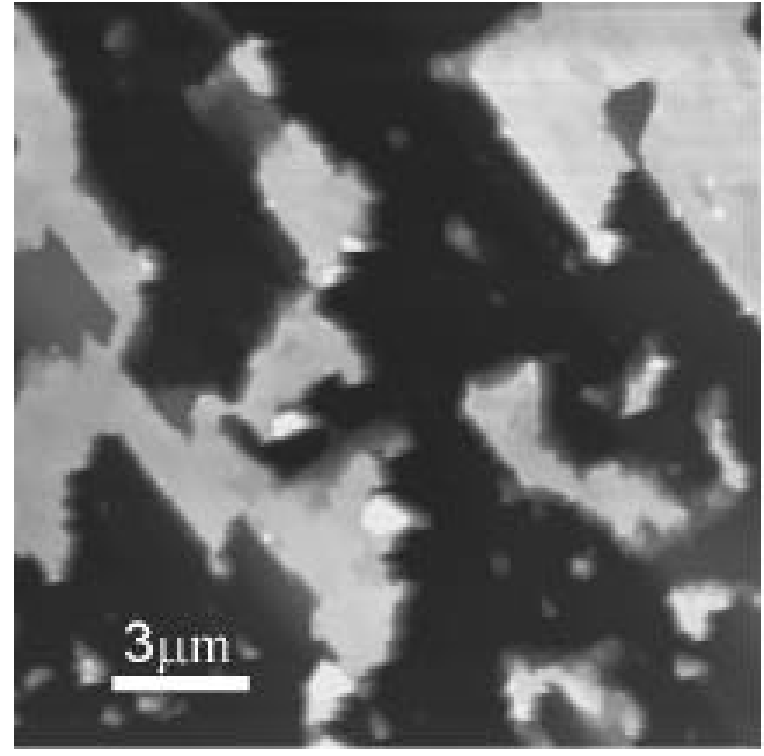

Figure 10: Image of the final product, $\delta$-HMX. The zscale is $1.2 \mu \mathrm{m}$ from light to dark. After this image, no significant morphological changes are observed at the surface. The formation of large pits and voids increases the shock sensitivity of $\delta$-HMX over that of $\beta$-HMX.

void to the terrace) of almost $100 \%$ is observed. In this case the step height starts at $363 \mathrm{~nm}$ in Fig. 9A and the final value is measured at $667 \mathrm{~nm}$ in Fig 9D. The cumulative void space volume increases from $0.8 \mu \mathrm{m}^{3}$ to $7.8 \mu \mathrm{m}^{3}$ in the $\delta$-phase. Fig. 10 shows a final image of $\delta$-HMX taken 2 hours from the start of heating at $184^{\circ} \mathrm{C}$. The crystal shows massive surface changes. After this point the material is fully

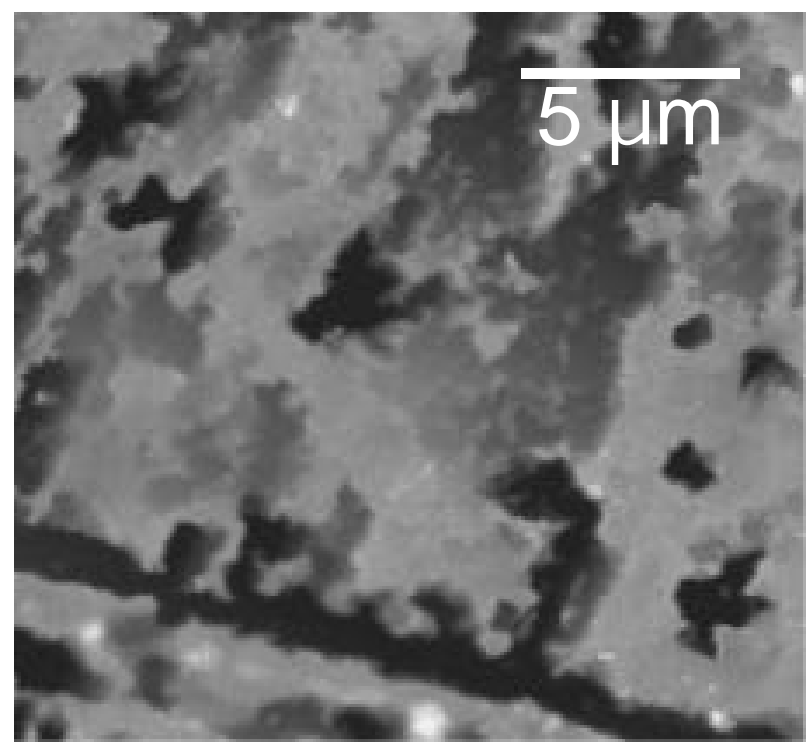

Figure 11: Partially converted surface of HMX. The main region where voids predominately formed is on a scratch that is evident in the lower section of the image. This suggests that local damage can contribute to the void formation process. converted and no further growth or change in the surface structure is observed.

The origin of the voids is not well understood. One plausible explanation is that defects diffuse throughout the crystal, accumulate and grow thus leading to the formation of voids. A more likely scenario is void nucleation propagates in areas of high local damage or stress fields. Perhaps voids in the $\delta$-phase are either remnants of hot spots where decomposition reactions started and died out or areas where sublimation of HMX molecules occurred. By conducting detailed thermal decomposition experiments, Behrens and Bulusu have shown that HMX does indeed decompose at temperatures as low as $182^{\circ} \mathrm{C}$ eluding $\mathrm{N}_{2} \mathrm{O}$ and $\mathrm{CH}_{2} \mathrm{O}^{20}{ }^{2}$ Evidence for the local damage mechanism is given in Figure 11 where the growth of voids occurs primarily at a scratch on the crystal surface, which can be observed in the lower section of the image. The change in the surface morphology is extreme. Table 1 shows the rms roughness and the local surface area between the starting material, Fig 4, and the final image, Fig 10. The roughness of the sample increases by $300 \%( \pm$ $75 \%)$ and the surface area increase by $15 \%( \pm 6 \%)$.

Table 1: Comparison of the rms roughness and the surface area of $\beta$-HMX and $\delta$-HMX as observe by AFM.

\begin{tabular}{l|c|c} 
& RMS roughness & Surface Area \\
\hline$\beta$-phase & $67 \mathrm{~nm}$ & $109 \mu \mathrm{m}^{2}$ \\
\hline$\delta$-phase & $299 \mathrm{~nm}$ & $123 \mu \mathrm{m}^{2}$
\end{tabular}

The change in the surface area and roughness is important to detonation physics issues, and may also help explain the discrepancy between SHG studies and XRD analysis. Harmonically generated light from the bulk of a crystal occurs when there is a lack of center of symmetry leading to light conversion at twice the frequency of the incident radiation. Typically the surface enhancement of SHG light intensity exceeds output intensity from the bulk process. $^{21}$ Our SHG/XRD experiments involve transmission mode data collection where buried interfaces contribute significantly to the SHG signal intensity. Surface defects have been shown to enhance the second harmonic signal. As an example SHG intensity was enhanced by a factor of $\sim 10^{4}$ on a roughened silver surface. ${ }^{22}$ The SHG surface effect has been used for over ten years to track protein conformational changes by generating SHG light at surface of cell membranes. ${ }^{21,23}$ The large surface area and total volume increase associated with the $\delta$-phase may enhance SHG conversion of the HMX crystal lattice. In addition the formation of liquid formaldehyde, $\mathrm{CH}_{2} \mathrm{O}$, decomposition product throughout the increased surface area of HMX grains would generate electric field discontinuities that 


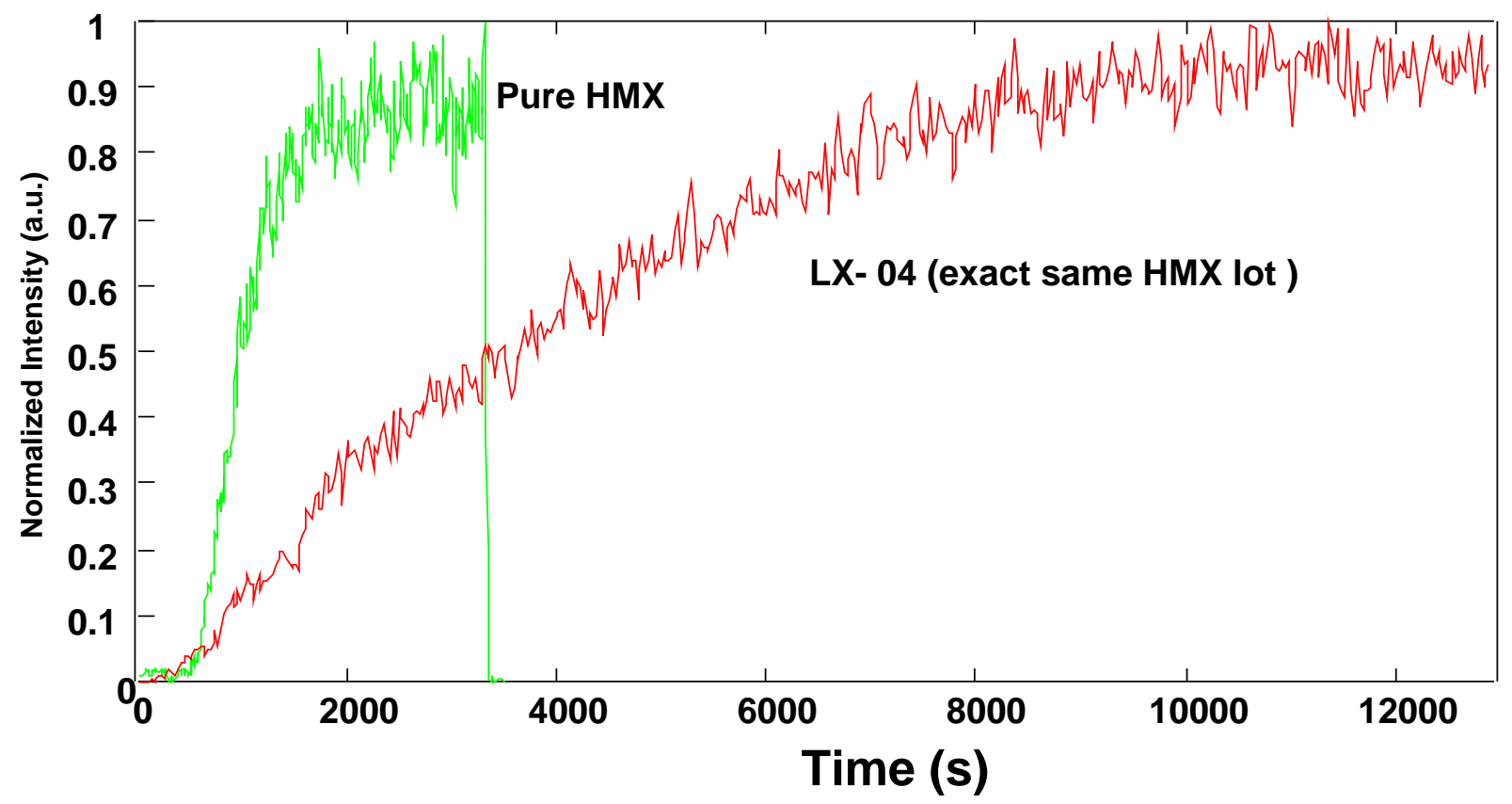

Figure 12: SHG intensity profiles for pure unpressed HMX and LX-04 powders at a constant temperature of $175^{\circ} \mathrm{C}$.

could exceed bulk generated SHG light intensity. It is certainly plausible that under the conditions responsible for the data presented in figure 8 . that chemical decomposition precedes the first-order structural phase transition.

Grain size effects may contribute to the incongruent contrast between our SHG and XRD data on HMX. We have conducted numerous survey XRD and SHG tests on relatively undamaged and larger HMX single crystals (50-200 micron length) and they phase convert almost instantaneously at a given temperature where as smaller crystals (0.1-20 microns) can take hours to convert at the same temperature. The data in figure 8 along with the grain size distribution shown in figure 3 could be interpreted that HMX grains less than 10 microns in diameter have yet to convert. It is perhaps the dramatic increase in surface area of phase converted HMX that accounts for the primary contribution in observed SHG intensity.

We would also like to note the effect a polymeric binder matrix has on the transition kinetics of HMX. The data presented in figure 12 demonstrates that for a fixed grain size distribution of HMX the presence of a polymer binder slows transitions by as much as a factor of four. The thermal expansion coefficient of Viton-A is approximately six times higher than that of HMX. We postulate that the thermally expanding polymer matrix imparts pressure to HMX grains. Increased pressure favors the stability of the lower volume $\beta$-phase of HMX and hence the observed retardation of $\delta$-phase growth.

\section{CONCLUSIONS}

High temperature XRPD and SHG experiments have been performed on TATB and HMX. For TATB, our results indicate no solid-solid phase transformation occurrence, even up to $340^{\circ} \mathrm{C}$ and this directly conflicts with the results of $\mathrm{S}$. Son et al. Our observed SHG signal strength at the start of the TATB experiment was quite strong ( 200 mV over background). Changes in TATB XRPD peak intensities are merely due to molecular re-arrangement and annealing effects. The molecular stacking distance relating to the c- lattice parameter increases with increasing temperature. No major peak changes in the (hk0) reflections are observed suggesting that there is no change in molecular conformation.

Our simultaneous SHG and XRD experiments on HMX show that SHG can give misleading results and this brings into question rates previously derived at Los Alamos for HMX and TATB using only the SHG diagnostic. Studying uniform grain sized HE materials (sample lot \# issues should be studied too) may give SHG a foothold concerning the rigorous determination of kinetic rate determinations for polymer blended explosive materials. A considerable amount of study must occur in order to learn exactly what SHG is monitoring in EMC or PBX systems.

Detonation theory suggests that 'hot spots' contribute to the decomposition process. ${ }^{24}$ Safety issues arise with $\delta$-phase HMX since increased void space measurably increases the shock initiated detonation sensitivity. Once initiated, hot spots either fail to react chemically due to thermal diffusion or react 
exothermically thus creating an ignition site in the solid explosive. These ignition sites then grow in temperature, size, and pressure leading to a deflagration or detonation depending on the physical and chemical properties of the material. Our AFM images quantitatively show increased void volume of HMX during conversion to the $\delta$-phase.

Currently, we are investigating the kinetic effects due to temperature and grain size on the conversion process. In addition to the sample topography TappingMode $^{\mathrm{TM}}$ AFM also provides mechanical properties of the sample by measuring the phase lag of the ac signal which may provide additional information on the nucleation of the void formation. These studies are being performed on all the faces of the crystal to provide a better understanding of the detonation and sensitivity of HMX.

We have taken optical movies where temperature is slowly ramping up that show, in some cases, where smaller crystals of HMX phase convert well before much larger crystals and vice versa. The reason for this apparent inconsistent behavior is that there is a threshold where defect density becomes the dominant precursor toward nucleation and growth process. In other words the free energy available for nucleation along internal voids and dislocations far exceeds that available at surface discontinuities. We intend to use AFM to monitor defect densities of HMX crystals while they grow in solution. We can control defect density by addition of impurities. It should be possible to determine a defect density threshold where one can discount grain size driven kinetics.

\section{ACKNOWLEDGEMENTS}

The authors would like to thank D. M. Hoffman for grain size distribution measurements and $\mathrm{C}$. $\mathrm{O}$. Boro, and D. G. Ruddle for assisting with the experimental setup at SSRL We thank P. Pagoria for HMX samples and M.F. Foltz for TATB samples. We are grateful for the assistance of C. M. Aracne Ruddle at SSRL and at Digital Instruments. Finally we appreciate D. J. Cook's guidance and instrument time at Digital Instruments.

*This work performed under the auspices of the U.S. Department of Energy by the Lawrence Livermore National Laboratory under contract number W-7405-Eng-48.

\section{REFERENCES}

1. H.H. Cady, A.C. Larson, and D.T. Cromer, Acta Crystallogr. 1963, 16, 617

2. R.E. Cobbledick and R.W.H. Small, Acta Crystallogr., Sect. B 1974, 30, 1918

3. P. Main, R.E. Cobbledick, and R.W.H. Small, Acta Crystallogr., Sect. C: Cryst. Struc. Commun. 1985,
4. A.G. Landers and T.B. Brill, J. Phys. Chem. 1980, 84, 3573

5. M. Herrmann, W. Engel, and N. Eisenreich, Propellants, Explos., Pyrotech. 1992, 17, 190

6. R.J. Karpowicz, L.S. Gelfand, and T.B. Brill, AIAA J. 1983, 21, 310

7. S.J.P. Palmer and J.E. Field, Proc. R. Soc. Lond. A 1982, 383, 399

8. Private conversations with Darren Naud at Los Alamos National Laboratory, 2002

9. Private conversations with Anita Runland at Sandia National Laboratory Albuquerque, 2002

10. Henson, B.F., Asay, B.W., Sander, R.K., Son, S.F., Robinsoon, J.M. and Dickson, P.M., Phys. Rev. Lett. 82, 1213-1216, 1999

11. Son, S.F., Asay, B.W., Henson, B.F., Sander, R.K., Ali, A.N., Zielinski, P.M., Philips, D.S., Schwarz, R.B. and Skidmore, C.B., J. Phys. Chem. B, 103, 5434-5440, 1999

12. G. Binning, C. Quate, Ch. Gerber, Phys. Rev. Lett. 1986, 56, 930

13. C.S. Coffey and J. Sharma, Phys. Rev. B 1999, 60, 9365

14. C.S. Coffey and J. Sharma, J. Appl. Phys. 2001, 89, 4797

15. J. Sharma, R.W. Armstrong, W.L. Elban, C.S. Coffey, and H.W. Sandusky, Appl. Phys. Lett. 2001, 78, 457

16. K.J. Davis, P.M. Dove, and J.J. De Yoreo, Science 2000, 290, 1134

17. M. Wiechmann, O. Enders, C. Zeilinger, and H.A. Kolb, Ultramicroscopy 2001, 86, 159

18. I. Reviakine, W. Bergsma-Schotter, A.N. Morozov, and A. Brisson, Langmuir 2001, 17, 1680

19. Digital Instruments, Veeco Metrology Group, Santa Barbara, CA 93117

20. R. Behrens and S. Bulusu, Mat. Res. Soc. Symp. Proc. 1996, 418, 119

21. Y. R. Shen, Nature 1989, 337, 519

22. C. Zhang, X. Xiao, N. Wang, K.K. Fung, M.M.T Loy, Z. Chen, and J. Zhou, Appl. Phys. Lett. 1998, 72, 2072

23. P. J. Campagnola, Mei-de Wei, A. Lewis, and L. M. Loew, Biophys. J. 1999, 77, 3341

24. C.M. Tarver, S.K. Chidester, and A.L. Nichols, J. Phys. Chem. 1996, 100, 5794 